\title{
Statistical Analysis of Aviation Accidents and Incidents Caused by Failure of Hydraulic Systems
}

\author{
Marta Woch ${ }^{1, a}$, Mariusz Zieja ${ }^{3}$, Justyna Tomaszewska ${ }^{2}$ and Mateusz Janicki ${ }^{2}$ \\ ${ }^{1}$ Institute of Aeronautics and Applied Mechanics, Warsaw University of Technology, Poland \\ ${ }^{2}$ Aviation Faculty, Polish Air Force University, Poland \\ ${ }^{3}$ Division for IT Support of Logistics, Air Force Institute of Technology, Poland
}

\begin{abstract}
In the era of globalization and permanent travel of people between far away regions of the world, air transport is one of the most important means of transport. Today it is also one of the most secure transport modes possibilities. Despite this, it is crucial to continuously improve the level of safety and reduce the absolute number of accidents and their victims. This idea stands at the beginning of the article subject creation and at the same time an attempt to further improve safety. The safety of the pilots and passengers plays a crucial role during air operations. One of the most important factors is the reliability of the aircraft. The main goal in the reliability work is to estimate the percentage of units of a product that will still be functioning after a particular period of time. In order to be able to make such a statement, it is necessary to select a probability distribution that will facilitate the construction of reasonably precise probability statements of the type that one wishes to make. In this analysis, the number of hours between failures has been used as the main variable for reaching the conclusion about the reliability of the aircraft at the selected examples.
\end{abstract}

\section{Introduction}

The constant growth of aviation and the increase in air traffic worldwide pose further challenges for the aviation industry to improve flight safety. To reach this goal, many specialists examine each air event in many aspects, creating different models, and looking for the best solutions to prevent risks. One of the tools for observing typical dangerous situations is statistical analysis $[1,2]$.

The aim of this contribution is to conduct a statistical analysis of the aircraft. It is assumed that the number of air events may depend on the time of year, the time of the air operations and the continent on which the flight will be performed $[3,4]$.

The motivation to undertake this subject was the interest in the safe movement of people in air traffic and the study of which factors have an impact on the safety of air operations.

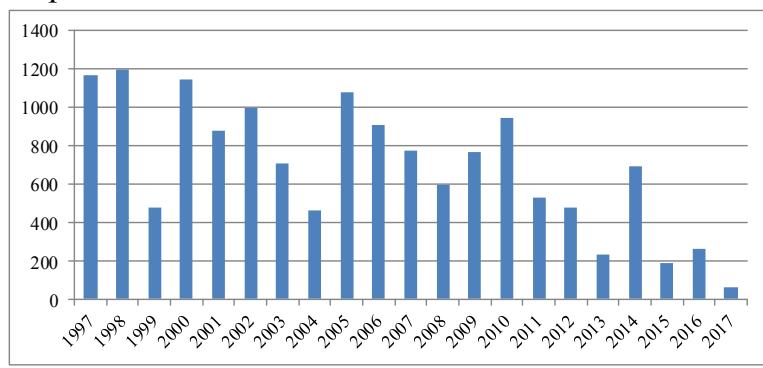

Figure 1. Number of fatalities in air accidents between 1997 and 2017.

\footnotetext{
${ }^{\mathrm{a}}$ Corresponding author: marta.woch@itwl.pl
}

Based on data from the Aviation Safety Network [5, 6], year 2017 was the safest year in the history of air transport. It should be noted that since 1997, the number of victims has decreased significantly from 1164 to 59 (Figure 1). There was no place in the world where there was an air crash involving commercial aircraft certified to carry at least 14 passengers (excluding sabotage and stripping), even though this year (2017) recorded the highest volume of air traffic in the history of air traffic [7-10].

Decrease in the number of air accident victims from 1164 in 1997 to 59 in 2017, is a proof that air travel is becoming safer and safer [11-13], which can partly be attributed to modern technological updates of aircraft, better safety procedures, and global cooperation to improve aviation infrastructure in developing countries.

\section{Methods of identifying causes of air events}

\subsection{James Reason's theory}

The effect of a human factor upon causes of air accidents is perfectly well explained with the James Reason's theory, who claims that safety within any system depends on the following factors [14]:

- strategy of performing actions at high management level, 
- actions at low management level,

- factors conducive to making errors,

- actions performed by the aircrew,

- lack of defences/safeguards to support the aircrew.

According to this theory, if factors hazardous to safety arise at every above-mentioned stage of activity and are not eliminated on time, an accident occurs. A model of how an air accident arises, according to James Reason, has been presented in Figure 2. In the presented model, latent hazards may be present at all stages of activity to reveal themselves in some specific circumstances only. For instance, e.g. decisions taken at high level of management to reduce health requirements, or give up requirements for some specific predispositions, or make some savings on aircrew-training costs may drastically translate into severe hazards to flight safety, under extreme conditions of the aircrew performing their duties, with the workload considerably exceeding their capabilities. On the other hand, improper behaviour/actions by aircrews and/or lack of suitable defences/safeguards can, but do not have to, bring about unfavourable effects. A systematic approach to solving problems of flight safety most fully reflects the (huge) amount of factors that directly or indirectly affect the occurrence of an air accident.

\section{JAMES REASON CUASATION MODEL}

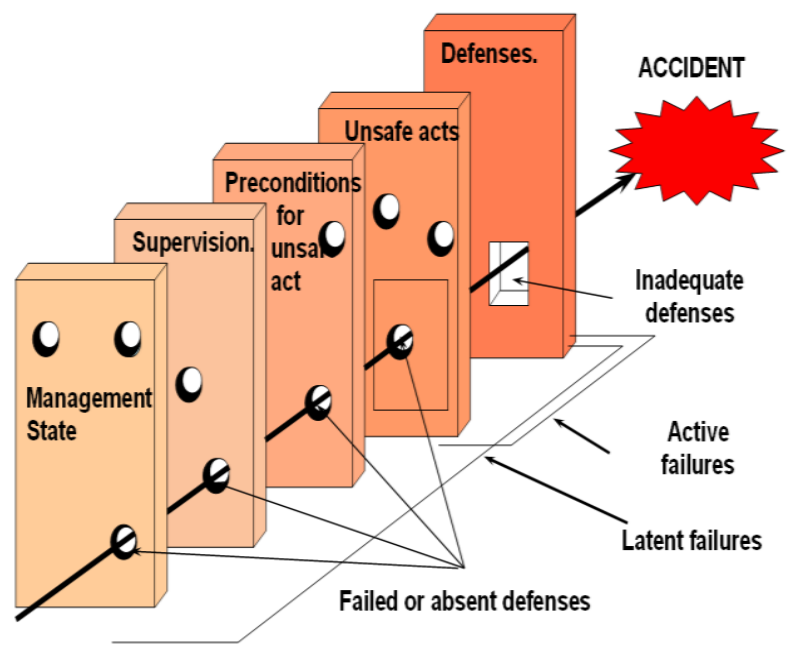

Figure 2. A model of how an air accident arises, according to James Reason.

There are four levels of causes of air events dependent on human actions [14]:

1. causes due to improper actions taken by the aircrew,

2. preconditions conducive to improper actions by the aircrew,

3. improper command/supervision, and its negative effect upon the aircrew,

4. improper management and its adverse effect upon the improper command/supervision and/or actions taken by the aircrew.

\subsection{James Reason's theory}

The SHELL model by Hawkins can be considered the basis for the interpretation of human (i.e. pilot-made) errors as factors underlying interactions of each of the SHELL components. It gives good grounds for the explaining, controlling, and predicting errors. Figure 3 shows a graphic form of the flight safety model according to Hawkins. Interactions of each of the model-included components are given consideration in the SHELL model (Fig. 4).

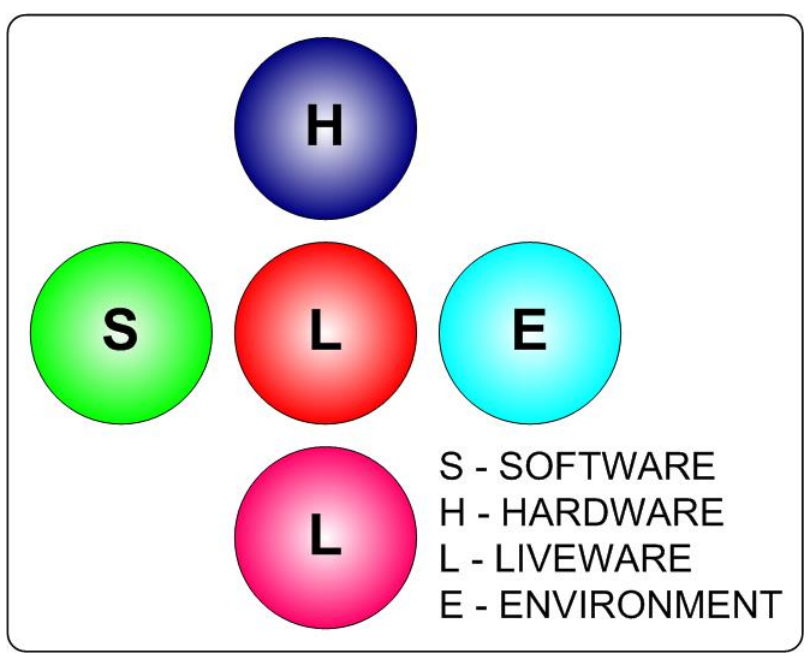

Figure 3. Systemic concept of flight safety model according to Hawkins

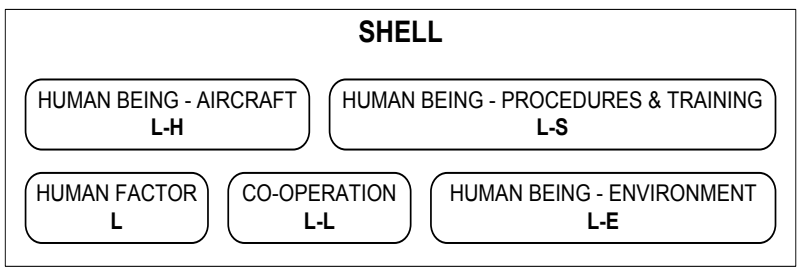

Figure 4. Interactions in the SHELL model

The L-H (human being - aircraft) interactions can be considered from five different aspects [14]:

- interactions that depend, among other things, on the cockpit equipment, ergonomic conditions (man-machine interactions), adjustments to human's features, and others;

- sources of information on the aircraft, accessibility, accuracy, readability thereof, uniformity, etc.;

- automatic control systems, whether the aircrew understand how to use them properly;

- aircraft warning systems, uniform and reliable signals, procedures, Traffic alert- and AirborneCollision Avoidance warning Systems (TCAS, ACAS);

- principles of operation in the field of maintenance oriented at the aircraft itself (as a whole), systems, devices/instruments, circuits, etc. following the so- 
called check-lists, precision of operating them, knowledge and observance of principles of operating on-board equipment, making correct use of the operational documentation.

Air accidents may be caused by disturbances in aircrew aircraft, or servicing staff - aircraft relationships.

In the case of the L-S interface (human being procedures and training) considered are interrelations between a human being on the one hand, and on the other hand, his/her level of training/education and applied procedures, and their probable contribution to causes of air accidents.

The liveware (L) and its contribution to causes of air accidents are considered from five different aspects [14]:

- physical: pilot's height, weight, level of training acquired, fit, strength, age;

- physiological: immunity to diseases, health, the way of life, resistance to hallucinations, resistance to fatigue;

- psychological: ability to act or lack of it, plan of activity, the way of making decisions, attention divisibility, predispositions, personal attitude, emotions;

- knowledge and experience: the scope of professional knowledge, flying experience, personal experience;

- workload: schedule of the day, work time, shift work, leisure, jet lag.

Co-operation between aircrew members and all who participate in the flight (the L-L interaction) is given consideration from four aspects:

- communication: verbal, in writing, visual signals, between aircrew members, with other aircraft, with the air traffic control, phraseology;

- the CRM/TRM (Crew Resource Management) aircrew co-operation, formal procedures, information transfer, crew members match;

- supervision: operational, in the course of training, taking care of quality, standards;

- rules and regulations in force - procedures, regulations, inspections, audits.

The L-E (human being - environment) interaction is given consideration from four aspects [14]:

- physical: airport/airfield, air navigation service, information, weather, work environment;

- psychological: satisfaction, morale, manners, family problems;

- functioning of the organisation: the set forth objectives, interrelationships, staff, HR policy;

- workload: excessive workload, time pressure.

\section{Statistical analysis}

\subsection{Forecasted deliveries of aircraft}

In response to the growth in air traffic forecast by ICAO, the two largest aircraft manufacturers, Boeing and Airbus, are planning to deliver around 69,000 new machines to their customers over the next twenty years (Figure 5):

- Boeing 42730 new planes [15],

- Airbus-26540 new aircraft [16].

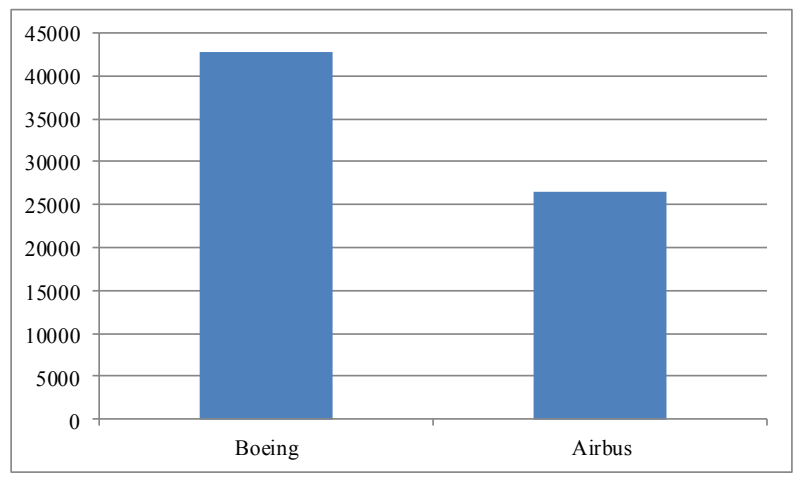

Figure 5. Forecasted delivery of aircraft by 2037.

All these mean that, with increasing air traffic, technology must be better than ever and precautions more stringent than ever before [17-19]. Many of these improvements can be attributed to the increasing efficiency and reliability of aviation technology, which has seen a reduction in the number of accidents caused by purely technical failures.

\subsection{Number of air events due to hydraulic system failure}

This work summarizes all the air events recorded so far, which were caused by the failure of hydraulic systems. Civil and military aircraft have been taken into account. All collected data comes from the database of "Aviation Safety Network" - a private, independent initiative established by the European Commission [5].

In 1996, covering accidents and safety issues in aviation, for passenger aircraft, military transport aircraft and corporate jets. Most of the information obtained from "Aviation Safety Network", comes from official sources.

A total of 73 aviation accidents and incidents were recorded, due to the failure of hydraulic systems. The first such air event was recorded in 1943, and the last one was recorded in 2015. The largest number of them took place in 1989, and in 1995 - each with 4 accidents. In the last three years, i.e. 2016 - 2018, there was not a single aviation accident caused by a failure of hydraulic systems (Figure 6). 


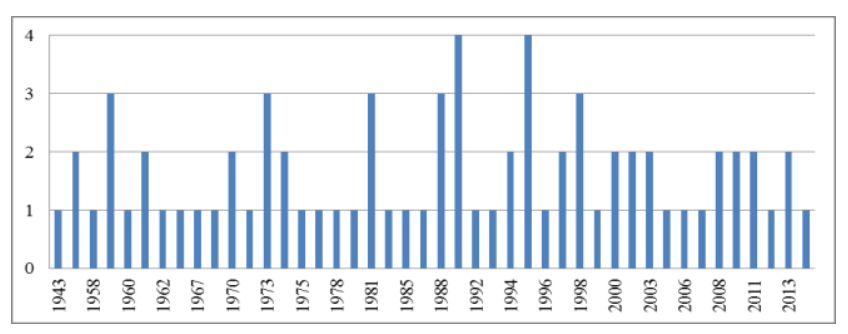

Figure 6. Number of air events from 1943 to 2015 caused by hydraulic system failure.

\subsection{Number of occurrences due to hydraulic system failure due to aircraft manufacturer}

Aviation accidents and incidents caused by hydraulic system failures occurred on machines belonging to 34 different aircraft manufacturers. Aircraft belonging to the American aviation company "Boeing" are the leader among the accidents caused by the failure of hydraulic systems. The following were noted 11 air events involving aircraft produced by this company. Slightly fewer air events occurred on aircraft belonging to "Douglas Aircraft Company" (10 cases), and the 'Lockheed Aircraft Company' (9 cases). The safest aircraft manufacturer, due to the air event caused by hydraulic system failures, turned out to be "Airbus". There was not a single accident and incident resulting from hydraulic problems in the machines of this manufacturer (Figure 7).

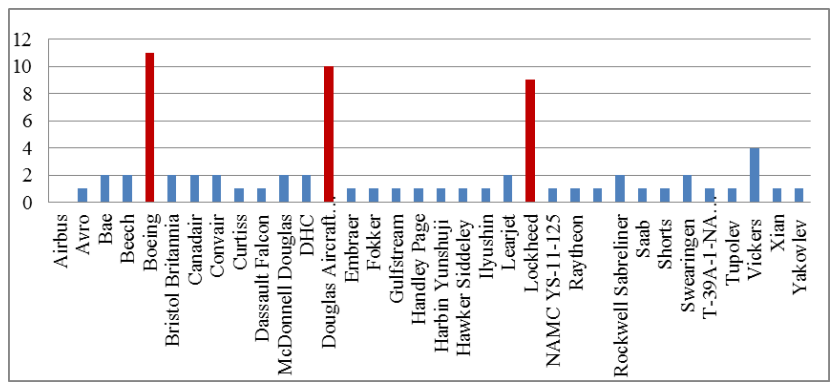

Figure 7. Number of air events caused by failure of hydraulic systems including aircraft manufacturers.

\subsection{Number of occurrences due to hydraulic system failure including phases of flight}

It was during the landing phase that the most incidents and accidents were recorded, including hydraulic system failures (Figure 8). There were as many as 47 air events in our database, including the aforementioned Boeing 767-300 emergency landing of LOT Polish Airlines in Warsaw.

The landing of an aircraft is the most difficult phase of the flight. It is a very complex process, in which the concentration of crew must be the greatest, due to the high complexity of the need to perform procedures in the cockpit. During landing, pilots are dependent on the altitude at which manoeuvrability is limited, as well as environmental, human or mechanical factors, e.g. size, weight of the aircraft, avionics.

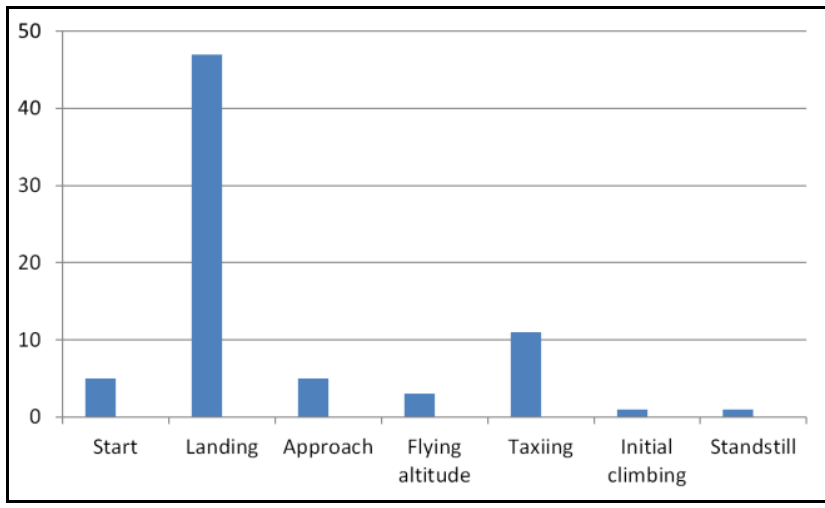

Figure 8. Number of air events caused by failure of hydraulic systems by phase of flight.

The most recent incident resulting from hydraulic system failure took place on 12 March 2015 at Blackpool Airport in the UK. "Raytheon 390" aircraft with four people on board, he flew from Avignon-Caum Airport in France to Blackpoool.

\section{Conclusions}

A statistical analysis of aviation accidents and incidents caused by failure of hydraulic systems has proved that, despite strict safety procedures in this mode of transport, such air events still occur. Their frequency is no longer as high and does not involve as many fatalities as in the past. None of these cases have been recorded in the last three years.

The United States is the country with the highest number of such air events, but it must be realised that the volume of air traffic is one of the highest there over the world. Every year the number of passengers travelling by air is increasing, which means that air carriers will have to gradually expand their fleet on new machines. On the basis of publicly available documentation, it has been shown, that manufacturers such as Boeing and Airbus will produce almost 69,000 new machines, which means that the number of their aircraft will be twice as many as before.

The United Airlines 232 catastrophe could have been more tragic if not the experience of the crew [20-23]. Until the last moments of this flight, the pilots fought against controllability with only two efficient engines at their disposal. This was not the only tragic cadastre in history with the same type of aircraft. Due to their design defects, further production of McDonnell Douglass DC10 aircraft was abandoned. The emergency landing of the Boeing 767 plane of LOT Polish Airlines in 2011 in Warsaw could have been prevented if the crew had noticed that the fuse responsible for powering the alternative chassis release had been pulled out. The National Aviation Accident Investigation Commission recommended that Boeing modify its checklists, including by adding a sub-point indicating the need to check the fuses if the alternative landing gear release system does not work. 


\section{References}

1. V. Talhofe, Š. Hošková, A. Hofmann, et al. The system of the evaluation of integrated digital spatial data reliability. 6th Conference on Mathematics and Physics at Technical Universities, Proceedings, pp. 281-288. ISBN 978-80-7231-667-0 (2009)

2. D. Valis, L. Zak, O. Pokora, Failure prediction of diesel engine based on occurrence of selected wear particles in oil, ENGINEERING FAILURE ANALYSIS, 56, pp. 501-511 (2014)

3. M. Hinz, F. Hienzsch, S. Bracke, Development of two methods for the characterisation of an automotive fleet behaviour based on the simulation of single car rides, RISK, RELIABILITY AND SAFETY: NNOVATING THEORY AND PRACTICE, pp. 1593-1598 (2017)

4. Z. Vintr, D. Valis, Modeling and analysis of the reliability of systems with one-shot items in ANNUAL RELIABILITY AND MAINTAINABILITY SYMPOSIUM, 2007 PROCEEDINGS.

5. Aviation Safety Network: https:/aviationsafety.net/statistics/period/stats.php?cat $=\mathrm{A} 1 \quad$ (access 15.03.2019)

6. M. Koucky, D. Valis, Reliability of sequential systems with a restricted number of renewals, Proceedings and Monographs in Engineering Water and Earth Sciences, pp. 1845-1849 (2007)

7. B. Babiarz, Aspects of Heat Supply Security Management Using Elements of Decision Theory, Energies, 11(10), 2764; doi:10.3390/en11102764 (2018)

8. V. Yu. Kozhevnikov, A. V. Kozyrev, N. S. Semeniuk, A. V. Batrakov, V. M. Karaban, D. S. Kosov Design and Diagnostics of Arc-resistant Electronics for Satellite Telecommunication Systems, 18th Mediterranean Electrotechnical Conference MELECON, 18-20 April 2016, Limassol, Cyprus, doi: 10.1109/MELCON.2016.7495441 (2016)

9. B. Babiarz, Heat supply system reliability management, Safety and Reliability. Methodology and Applications, TAYLOR \& FRANCIS GROUP p. 513-520. London (2015)

10. L. Hynčík, T. Bońkowski, J. Vychytil, Virtual hybrid human body model for PTW safety assessment. Applied and Computational Mechanics, , 11 (2), pp. 137-144. ISSN: 1802-680X (2017)

11. L. Hynčík, T. Bońkowski, W. Lyu, Development of a simple motorcyclist helmet finite element model. International Journal of Vehicle Safety, 10, 3/4, pp. 277 - 287, doi: 10.1504/IJVS.2018.097720 (2018)

12. B. Babiarz, P. Kut, District heating simulation in the aspect of heat supply safety. VI International Conference of Science and Technology INFRAEKO
2018. Modern cities. Infrastructure and Environmental, Cracov, E3S Web of Conferences 45, 00005 (2018)

13. W. Lv, L. Hyncik, T. Bonkowski, Rider Stature Influence to Injury Risk in Motorcycle Rear Impact to Car, SAE Technical Paper 2019-01-1436, , https://doi.org/10.4271/2019-01-1436 (2019)

14. J. Żurek, Z. Smalko, M. Zieja (2010). Methods applied to identify causes of air events. Reliability, Risk and Safety: Theory and Applications. TAYLOR \& FRANCIS GROUP p. 1817-1822. London (2010)

15. Boeing: https:/www.boeing.com/commercial/market/comme rcial-market-outlook/ (access 15.03.2019)

16. Airbus:

https:/www.airbus.com/aircraft/market/globalmarket-forecast.html (access 15.03.2019)

17. F.Maturo, Š. Hošková-Mayerová, Fuzzy regression models and alternative operations for economics and social sciences. Recent Trends in Social Systems: Quantitative Theories and Qualitative Models. Book of Series: Studies in Systems, Decision and Control, 66, pp. 235-247. DOI:10.1007/978-3-319-40585$8 \_21$ (2017)

18. A. Mueller, M. Hinz, S. Bracke, Optimization of the dental implant testing based on FEM simulation of fatigue and accelerated life, RISK, RELIABILITY AND SAFETY: INNOVATING THEORY AND PRACTICE, pp. 16-22 (2017)

19. Š. Hošková-Mayerová, Education and training in crisis management. The European Proceedings of Social \& Behavioural Sciences EpSBS, XVI, pp. 849-856. DOI:10.15405/epsbs.2016.11.87 (2016)

20. V.Yu. Kozhevnikov, N. Semeniuk, A.V. Kozyrev, V.M. Karaban, D.S. Kosov. Novel Automated Software System for Arcing Simulation in Spacecraft On-Board Electronics. $2017 \quad$ International Conference on System Reliability and Science (ICSRS), 20-22 December 2017, Milan, Italy, pp. 469-473, doi: 10.1109/ICSRS.2017.8272867 (2017)

21. A. Kalinska, A. Wojcik, J. Slosarz, Occurrence and aetiology of Staphylococcal mastitis - a review, Animal Science Papers And Reports, 36,3, pp.263273, 2018.

22. M. Hinz Concept for Machine Learning and Field Data driven Adjustment of Testing Conditions of Technical Prototypes (Berichte aus der Zuverlässigkeitsanalytik und Risikoforschung, Band 3) Shaker Verlag, ISBN- 13: 978-3844060225 (2018)

23. A. V. Kozyrev, V. Y. Kozhevnikov, N. S. Semeniuk, L. A. Zyulkova. Theoretical Simulation of a Gas Breakdown Initiated by External Plasma Source in the Gap With Combined Metal-Dielectric Electrodes. IEEE Transactions on Plasma Science, 43, 8, pp. 2294-2298,doi: 10.1109/TPS.2015.2447032, (2015) 